\title{
RETHINKING THE EVENTFUL CITY: INTRODUCTION
}

\author{
GREG RICHARDS* AND ALBA COLOMBO† \\ *Academy for Leisure, NHTV, DX Breda, The Netherlands \\ †Arts and Humanities Department, Universitat Oberta de Catalunya, Barcelona, Spain
}

The "eventful city" concept developed out of the basic observation that cities are using events to achieve a growing range of policy objectives, including economic growth, image change, social cohesion, and physical redevelopment. The growing importance and scale of event activity in cities is driving rapid change in the relationship between events and the city. Cities are no longer simply containers or stages for events; they are cocreators, innovators, directors, managers, partners, and beneficiaries of events. Events in turn are shaped by the cities they take place in, with their form, duration, content, and effects being determined to a large extent by urban space, place, and process.

The eventful city concept was first set out by Richards and Palmer (2010), who defined an eventful city as one that purposefully uses a program of events to strategically and sustainably support long-term policy agendas that enhance the quality of life for all. Since then, the volume of research on cities and events has grown enormously. Much more attention is being paid to the development of urban event policies, stakeholder networks and regimes, and the development of event portfolios. All of this work has added to our understanding of how eventful cities are developed and function. It has also called into question some of the original premises of the eventful city concept, which is therefore in need of expansion and revision. This was the basic aim of the expert meeting on Rethinking the Eventful City: Perspectives, Practices, Prospects organized by the Association for Tourism and Leisure Education and Research (ATLAS) in Barcelona in 2016.

Few cities illustrate the dialectic relationship between cities and events better than Barcelona. Starting with the World Expo in 1888 and continuing through the 1929 World Expo and the 1992 Olympic Games, Barcelona has harnessed the power of events to put itself on the global map, shape perceptions, and drive economic, cultural, and social development. With the Mobile World Congress attracting over 100,000 visitors in 2016, and agreeing to come back to the city for a further 8 years, Barcelona is rapidly establishing itself as a global events hub.

This development has not always been smooth or entirely progressive. The forging of an economic growth coalition in post-Franco Barcelona helped to secure the Olympics, but the focus events to drive external promotion and economic growth has attracted increasing criticism from social partners and local citizens concerned with the globalization of the city and the loss of identity. One of the basic questions to emerge from the meeting was: Do events serve the city, or does the city serve events? 
When the original eventful cities concept was developed a few years ago, few cities had experience of managing, developing, and directing their event programs to produce effective outcomes. However, in recent years different models have emerged that show how cities can develop a constructive relationship with their events, and how the events can benefit from this relationship as well.

More research has consequently emerged dealing with events and the cities they use and are used by. Event Management has published a growing number of articles related to events and cities. For example, there have been a number of recent studies considering the effects of the Olympic Games in different cities (Emery, Kerr, \& Crabtree, 2016; Fairley, Gardiner, \& Filo, 2016; Potwarka, Tepylo, Fortune, \& Mair, 2016). Other events such as the ECOC have also been analyzed in their urban context (Vareiro, Santos, Remoaldo, \& Ribeiro, 2016). Zhou, Qiao, and Ryan (2017) analyzed the use of events by Chinese cities to gain competitive advantage, and Boyle, Reaiche, Abdullah, and Murad (2016) examined the role of art events in Hong Kong in stimulating international visitation. Gration, Raciti, Getz, and Andersson (2016) analyzed valuation of events in the Sunshine Coast of Queensland, adopting the events portfolio approach earlier outlined by Ziakis (2013).

Elsewhere, Smith has produced two monographs examining different aspects of the relationship between events and the city. In Events and Urban Regeneration, Smith (2012) examined the ways in which cities have strategically used events for regeneration purposes. In Events in the City, Smith (2015) examined the potential problems stemming from the growing use of parks and other public spaces for events. An interesting contribution to the growing literature on event cities was made by Wynn (2016), who developed a "sociology of occasions" in analyzing the emergence of music/city alliances in the US. He concentrated on the cities of Nashville, Austin, and Newport, all of which have been transformed by music events. He shed light on the different spatial forms that major events can take in cities, including what he referred to as "citadel," “core," and "confetti” patterns.

This body of work shows that the eventful cities field is attracting interest from a growing body of scholars from different regions and disciplinary perspectives. This was also evident from the range of articles presented at the ATLAS Events Group meeting in Barcelona. The aim of the ATLAS meeting was to review the development of "eventful cities" such as Barcelona, to analyze the emerging trends in the eventful landscape, and to trace potential future development directions. The meeting brought together leading international scholars in the event studies field, including many long-time members of the ATLAS Events Group. The meeting was hosted by the Open University of Catalunya (UOC) in Barcelona, and they also arranged a keynote presentation from Don Getz to launch the event. Alba Colombo and her team from the UOC did a great job of facilitating the working sessions as well as the social program of the event. The topics covered ranged from theoretical think pieces about eventful cities to studies of event portfolios and specific case studies of urban events and their effect on host cities.

In the first article Greg Richards outlines the development of the eventful city concept, and how this has led to more holistic approaches to event programs and portfolios in many cities. The article identifies three ideal types of city-event relationships: Event-centric policy, sector-centric policy, and network-centric policy, which are illustrated with reference to cities such as Edinburgh and Antwerp (event-centric), Montréal and Rotterdam (sector-centric), and 's-Hertogenbosch and Barcelona (network-centric). Each of these ideal types tends to relate to a different set of governance arrangements.

Vladimir Antchak and Tomas Pernecky also compare different cities in their review of approaches to portfolio design in New Zealand. The cities of Auckland, Wellington, and Dunedin are compared in terms of different parameters of their events portfolio: Formality, intentionality, directionality, and rhythmicity. They find that the context of the different cities plays a key role in shaping portfolio approaches. For example, the smaller size of Dunedin means there is less directionality in the portfolio, and this creates more space for community input in comparison with the larger cities of Auckland and Wellington.

Alba Colombo also considers the link between events and urban policy agendas in her analysis of the event landscape in Barcelona. She argues 
that the development of eventfulness can be best understood by examining the link between urban policies and specific sectors of event activity. Taking music festivals as an example, she shows how changes in policy have affected the relationship between the Municipality of Barcelona and two major music festivals. She suggests that Barcelona has moved away from a holistic "eventful city" approach towards a more focused use of festivals to attain specific policy aims in different areas of the city.

Don Getz, who draws on experiences from Sweden to illustrate the challenges involved, analyzes the sustainability of event cities. Getz argues that cities should consider the health of their whole population of events in order to create sustainable event portfolios. Cities need to create a supportive environment for events, and ensure that events are a positive force in working towards green and sustainable policies. Long-term sustainable growth or value creation should be the main aim in portfolio design for eventful cities.

Ilja Simons examines the sustainability of event practices in the context of the Incubate Festival in the city of Tilburg in the Netherlands. Using ethnographic methods, she analyzes the fit between the Incubate event and the policy context of the city, showing that although the event itself is very successful in artistic terms and beloved by attendees, it fails to deliver the image impacts demanded by the city. This has led to a cessation of public funding, which will probably lead to the demise of the festival. These points to the growing problems that events face in meeting the demands of instrumental events policies, and illustrates those eventful city policies may not lead to more eventfulness.

Andrew Smith highlights the challenges involved in staging major events in public spaces in cities. Drawing on the experience of London, he analyzes how parks have become a frequent stage for events, challenging widely held ideas about the role of city parks as public space. Although major events can generate much-needed revenue, ticketed events restrict access, leading to privatization, commercialization, and securitization. Smith concludes that these processes are increasingly driven by a neoliberal agenda linked to place marketing and revenue generation, which can undermine the public function of the parks.
In the final article, Alba Colombo and Greg Richards examine the ways in which eventful cities can act as catalysts for innovation on a global scale. Taking the example of the Sónar Festival in Barcelona, they show how an event that emerged from a very specific local context has managed to turn itself into a model for music events worldwide. This has been made possible by a very deliberate policy of cloning and adaptation on the part of the festival organizers, who see the globalization of the event as a means of increasing the profile and power of the original event in the "hub" of Barcelona.

Taken together these contributions illustrate many of the dimensions along which the original eventful city concept is being reproduced and rethought. One clear theme that emerges from a number of articles is the apparent link between more centralized models of the eventful city and neoliberal policies and governance regimes. Andrew Smith's contribution raises very specific fears about the negative effects of the commercialization of public space, although Alba Colombo's analysis of recent events in Barcelona suggests that this trend is not irreversible.

Cities everywhere seem to encounter problems with the sustainability of their event programs, or of individual events within those programs. Don Getz underlines the need to see sustainability as an issue of the entire population of city events. This more ecological approach to the study of event programs contrasts with the financial management origins of the event portfolio approach. Some of the articles in this special issue suggest that events in a city interact with and affect each other, producing an ecology of events that may be less amenable to the relatively top-down portfolio approach. On the other hand, there is also evidence that events also compete with each other for limited resources (funding, space, and other forms of support) within the city.

Even though the public sector may be playing a less prominent role in event funding due to financial constraints, the administration still has a key role in distributing other resources, particularly in controlling the use of public space. As Andrew Smith shows in his discussion of events in public parks, financial pressures may lead to a commercialization of these and other public spaces and a growing festivalization of cities. The term festivalization often has negative connotations, being connected 
with shallow, commercial, and privatized events. However, as Wynn (2016) has recently argued, festivalization can also have a positive effect if it can provide the stimulus for cultural production and creative activities that feed social cohesion and sustainable economic growth.

This rethinking of the eventful city concept can also be a catalyst for further research. The growth of cities will inevitably lead to more urban events, and to more cities needing to think about how to manage their events program. In the current "urban century," we might be prompted to ask the question whether city-based events are different or distinct because of their urban context, or if such events are becoming more and more alike. How will the relationship develop in the future, particularly as emerging cities in the developing world become more important as event spaces? Not just the more formal spaces such as parks and squares found in European and North American cities will be important for events, but also the more informal public spaces of the favela or township (Haferburg \& Steinbrink, 2017). Such spaces have been marginalized or made invisible for major events (Campos, 2017)—how can this be challenged in the future?

One article presented at the Barcelona meeting by Sompong Amnuay-ngerntra dealt with arts events in Thailand, and this highlighted the fact that the relationships between cities, events, and culture in Western societies are not the same as those in Asia. One of the future challenges for the ATLAS group and other event scholars is to encourage more exchange of ideas between scholars working in the dominant European and North American paradigms and those from other world regions.

Many of the articles in this special issue also set out ideas for future research agendas. For example, Vladimir Antchak and Tomas Pernecky argue there is a need to further enhance our understanding of event portfolios in different sociocultural, political, and historic contexts. They also suggest that event networks in different cities should be analyzed to see how different interests and perspectives interact and affect event portfolios. Andrew Smith also suggested that the distribution of costs and benefits related to eventful city policies need to be more carefully explored. Holding commercial events in public spaces may help to provide funding for those spaces, but it can also mean that local residents are exposed to increased noise and congestion. Studying the effects of eventfulness in different types of urban spaces would also help to increase our understanding of the production of urban space. As Ilja Simons points out, events are capable of creating their own "third spaces," which allow new things to happen. The third space created by the Incubate Festival in Tilburg is mainly inhabited by the in crowd of festivalgoers, and these spaces are effectively invisible to others. However, for other events the creation of third spaces may be a deliberate way of creating new connections between groups within and without the city.

Don Getz suggests a number of possible directions for new research, including comparisons of cities in terms of their supportiveness of events and their ability to achieve sustainable event outcomes. He also suggests a need to compare whole city event populations or portfolios, which necessitates measurement of the value that different events generate for the city. Greg Richards also suggests the measurement of value in a network context. To what extent can networks of events generate more value for cities than single events? Colombo and Richards also point out that the ability of some cities to create a "hub" function for themselves is likely to increase the value they can leverage from specific events. More research is needed to chart the network connections between events in different cities and to understand how these events create value for their host cities as well as each other. Such research is likely to become more important as events try to grow through the production of new editions in different cities. As in the case of the Sónar Festival, many other events are trying to extend their profile internationally. Music festivals such as Rock in Rio (Rio de Janeiro and Lisbon), Primavera Sound (Barcelona and Porto), or Lollapalooza (Chicago, Buenos Aires, Sao Paulo, Santiago de Chile, Berlin, and Paris) have become globalized, raising the question of whether the brand value of the event is more important than that of the city it is held in. To what extent will eventful cities compete in the future to attract big name events to fill their event programs? These are no doubt questions that will continue to be debated by the ATLAS Events Group and in the pages of Event Management. 


\section{References}

Boyle, S., Reaiche, C., Abdullah, A., \& Murad, W. (2016). Predicting international visitors' interest in Hong Kong Arts Festival. Event Management, 20(4), 593-605.

Campos, R. (2017). On urban (in)visibilities. In J. Hannigan \& G. Richards (Eds.), The SAGE handbook of new urban studies (pp. 232-249). London, UK: SAGE.

Emery, P. R., Kerr, A. K., \& Crabtree, R. M. (2016). Critical incidents, emotions, and value-added moments: The London 2012 spectator experience. Event Management, 20(4), 517-535.

Fairley, S., Gardiner, S., \& Filo, K. (2016). The spirit lives on: The legacy of volunteering at the Sydney 2000 Olympic Games. Event Management, 20(2), 201-215.

Gration, D., Raciti, M., Getz, D., \& Andersson, T. D. (2016). Resident valuation of planned events: An event portfolio pilot study. Event Management, 20(4), 607-622.

Haferburg, C., \& Steinbrink, M. (2017). Mega-events in emerging nations and the festivalization of the urban backstage: The cases of Brazil and South Africa. In J. Hannigan \& G. Richards (Eds.), The SAGE handbook of new urban studies (pp. 267-290), London, UK: SAGE.

Potwarka, L. R., Tepylo, H., Fortune, D., \& Mair, H. (2016). Launching off but falling fast: Experiences of becoming more physically active in response to the Vancouver
2010 Olympic Winter Games. Event Management, 20(3), 297-312.

Richards, G., \& Palmer, R. (2010) Eventful cities: Cultural management and urban revitalisation. London, UK: Routledge.

Smith, A. (2012). Events and urban regeneration: The strategic use of events to revitalise cities. London, UK: Routledge.

Smith, A. (2015). Events in the city: Using public spaces as event venues. London, UK: Routledge.

Vareiro, L., Santos, J. F., Remoaldo, P. C., \& Ribeiro, J. C. (2016). Evaluating the Guimarães 2012 European Capital of Culture: National and international tourists' behaviors and perceptions. Event Management, 20(1), 81-97.

Wynn, J. R. (2016). Music/city: American festivals and placemaking in Austin, Nashville, and Newport. Chicago, IL: University of Chicago Press.

Zhou, C. N., Qiao, G., \& Ryan, C. (2017). How might Chinese medium sized cities improve competitive advantage in the event tourism market? Event Management, 21(1), 109-118.

Ziakas, V. (2013). A multidimensional investigation of a regional event portfolio: Advancing theory and praxis. Event Management, 17(1), 27-48. 
Copyright of Event Management is the property of Cognizant, LLC and its content may not be copied or emailed to multiple sites or posted to a listserv without the copyright holder's express written permission. However, users may print, download, or email articles for individual use. 